in a particularly minute form. On the other hand, Lieutenant Christophers has shown that the parasites are frequently to be found in papules in the skin, especially on the thighs and other parts usually protected by the clothes from mosquitoes but still open to the attacks of fleas and of the still more blood-thirsty bugs. That the stomachs of the latter are well adapted for the development of the parasites I have indicated above, and although so far I have failed to find the parasites in bugs from the beds of patients suffering from cachexial fever in Calcutta and from kala-azar in Assam (the latter having been kindly supplied me by my friend Mr. J. Dodds Price, although they could not be examined until after a four days' journey), still I am of the opinion that bugs are the most likely carriers of the disease. That they abound in the wooden beds of natives, especially in Bengal and Assam, is quite certain, while they are also a pest in the poorer native and Eurasian houses and even in native hospitals. Further work to test this hypothesis is very necessary, but I venture to think that the probability of the bug or flea being the usual carriers of the disease is sufficiently great to render it advisable to take steps to prevent the possibility of infection being carried in this way. This may be done by recognising the communicability of even the endemic cachexial fever and preventing any infected and uninfected persons sleeping in the same bed or in adjoining beds placed close together, as is such a common custom in India. This precaution is specially desirable in the case of children who are very susceptible to the disease and in whom it is also exceptionally fatal, children under ten years in particular but seldom recovering from it.

In conclusion, I desire to express my thanks to Lieutenant-Colonel Harris and Lieutenant-Colonel Drury, I.M.S., for their very kind permission to make use of their cases and to Captain D. McCay, I.M.S., and Captain J. W. D. Megaw, I.M.S., for much help in examining cultures and for many valuable suggestions.

Calcutta.

\section{A CASE OF WIDESPREAD ULCERATION OF SKIN AND CONNECTIVE TISSUE.}

BX W. BERTRAM WATSON, M.D. LOND.,

HONORARY PHYSICIAN TO THE YORKSHIRE HOME FOR INCURABLE AND CHRONIC DISEASES, H.ARROGATE.

IN this paper it is proposed to give some short notice of a case of ulceration of skin and connective tissue which bas recently come under my observation. The patient was a man, aged 61 years, employed in business, and came under my care in August, 1904 . But for a somewhat severe attack of influenza 16 years and of pleurisy six years previously, he described himself as having been a healthy man up to the onset of the skin affection shortly to be described. He had never had syphilis and there was no family history of tubercle.

With regard to the skin affection, the patient gave the following history. In 1900 he noticed a small lump in the left buttock which slowly and painlessly increased in size and was followed in March, 1901, by a second lump which developed a little higher and nearer to the spine. Both of these ultimately burst. Shortly afterwards lumps began to form in the left groin and in August, 1901, recourse was had to surgical treatment, the lumps in the back and a number of enlarged glands from the groin being removed and the parts scraped by the late Mr. T. R. Jessop of Leeds. The result of this treatment was not satisfactory and ten weeks later the scraping was repeated. After a few months these places healed, but coincident with the improvement in these situations the disease showed itself in other localities. The course from now onwards was a progressively downward one. The skin gave way in a number of places at the back of the right chest and in the loins; early in 1902 he had considerable pain in the right shoulder and arm which was followed by inflammation of skin which broke down in numerous places and formed running sores. The same process commenced in the skin of the right leg in April, 1903, and the left leg became involved in July of the same year. From 1902 he had been compelled to lead a life of invalidism, could walk only with difficulty, and had considerable pain. His general health suffered in consequence and the body weight fell from 11 stones 7 pounds in 1900 to 9 stones in August, 1904.

The accompanying illustration will give some idea as to the character and extent of the skin lesions in August of last year. The patient could move only with considerable pain The complexion was sallow and the blood, as evidenced by the colour of the lips and conjunctiva, was deficient in hrmoglobin. Contrary to what one would have anticipated there was no evidence of lardaceous disease and the lungs, kidneys, and other organs appeared to be healthy. In no situation were the lymphatic glands markedly enlarged. It is not necessary to give a minute description of the condition of the skin. Many of the ulcers were deep and their bases where visible were seen to be irregular, yellow, and unhealthy. They were in varying degrees of inflammatory

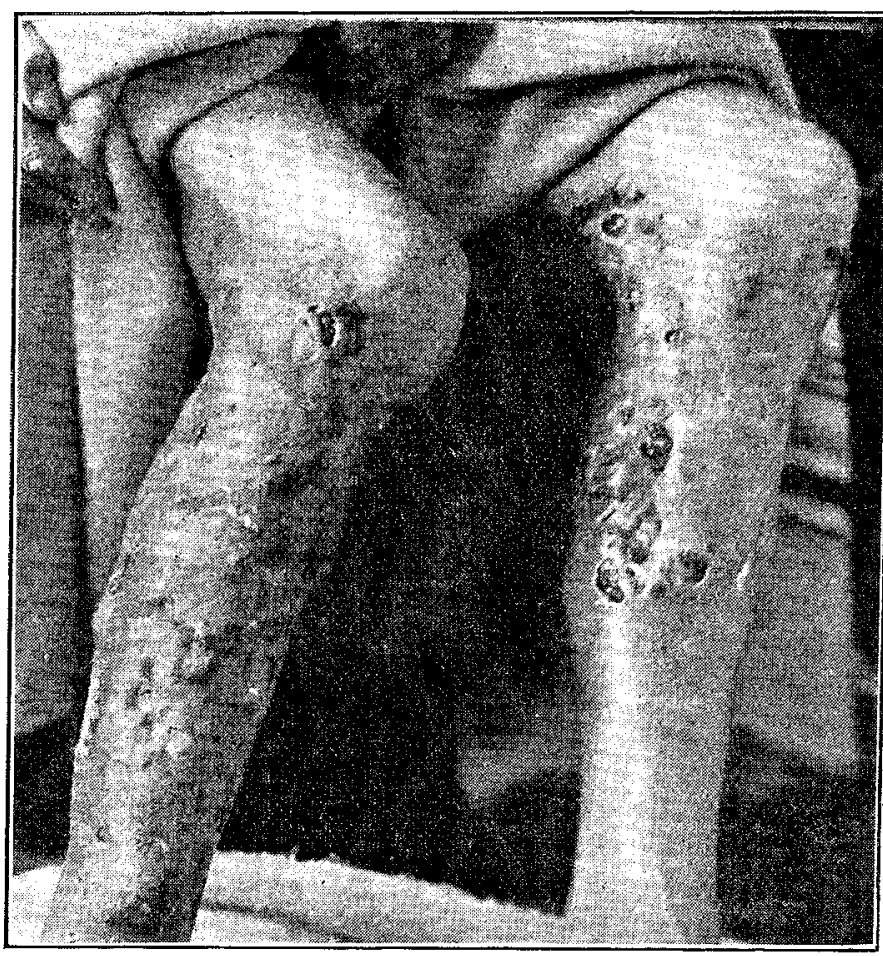

activity, with thin, ragged, undermined edges, and exuding thin, dirty-white pus. Some, which had entered into a quiescent state, were filled with yellowish-white grumous material. Between the skin and the bone over the shin of the right leg were several soft, semi-fluctuant tumours. On the back were scars indicating that in these situations the process of repair had been successful. With the presence of sinuses and numerous bunches of flabby, unhealthy granulations the character of the lesions, which was the same in all the localities affected, presented a complete clinical picture of tuberculous ulceration of the skin and connective tissues.

When the question of treatment came to be considered it appeared that the only possible chance of success was by means of radical surgical measures. Abscesses should be opened, fungating granulations and ulcers scraped, undermined skin cut away, and sinuses freely laid open. This would have required a series of operations under anæsthesia, which would have proved no light matter in a subject 61 years of age, exhausted by prolonged illness. This line of treatment, which was advised, was not, however, adopted as the patient was not willing to submit himself to further surgical interference. Accordingly he was kept at rest in bed and his constitution was strengthened by an abundance of good food, combined with cod-liver oil, syrup of iodide of iron in full doses, and other tonics. The ulceration of the skin was treated on ordinary antiseptic lines by means of poultices, fomentations, and dusting powder as each in turn seemed to be indicated. The arms and legs were placed in a bath for one hour daily containing lotions, carbolic acid and chinosol, perchloride and biniodide of mercury being the antiseptics used. I found that Fairchild's enzymol was of special service in clearing away dead material in deep ulcers. Salicylic cream (acidi salicylici, two parts ; acidi carbolici, one part; glycerine, ten parts) also proved useful. For dusting powder I made use of equal parts of iodoform and dermatol. On one occasion with the aid of local anæsthesia I incised one of the semi-fluctuant tumours over the shin, to which reference has already been made, and found it to contain 
curdy material. The effect of this treatment was remarkable. In a few days the ulcers cleaned and the purulent discharge diminished in quantity. The process of repair in the ulcerated surfaces was very rapid and after two months' persistent local disinfection the back, and after four months the whole of the areas involved (back, arm, legs) had completely healed. It is not necessary to give illustrations of the present condition as all they would show is extensive cicatrisation.

At the time of writing the patient is in excellent health. He is able to attend to business and his weight has increased to 11 stones. I thought that owing to contraction of cicatricial tissue walking would prove a difficulty and that it would be necessary to do something in order to free the action of the knee-joints. However, no further treatment of this kind has been required as their movement is quite free.

In conclusion, it may be mentioned that it was the opinion of the late Mr. Jessop, when he operated, that the case was tuberculous in origin.

Harrogate.

\section{THE OPERATION OF JEJUNOSTOMY,} WITH A DESCRIPTION OF A NEW METHOD. ${ }^{1}$

By A. W. MAYO ROBSON, D.Sc. LEEDS, F.R.C.S. ENG., SENIOR VICE-PRESIDENT OF THE ROYAL COLLEGE OF SURGEONS OF ENGLAND.

JeJurostomy is an operation occasionally called for as a means of giving relief and prolonging life in patients suffering: from advanced disease of the stomach, where on exploration it is discovered to be impracticable to perform gastrectomy, gastrostomy, or gastro-enterostomy. The indications for the operation are (1) extensive cancer of the stomach too advanced for gastrectomy and in which no healthy "spot of sufficient size on the stomach wall can be found for the purpose of gastrostomy or gastro-enterostomy ; and (2) general cicatricial contraction of the stomach, simple in character and due to the swallowing of caustic fluid, in which the stomach has been so far damaged that it no longer performs its functions or even allows of the proper passage onwards of food. It has also been suggested in pronounced hyperchlorhydria in preference to gastro-enterostomy in order to avoid peptic ulcer of the jejunum, but as the latter is extremely rare and practically only associated with anterior gastro-enterostcmy, a method that is being replaced by the posterior operation, I do not think surgeons generally will be likely to endorse Neumann's suggestions; nor do I think that it is probable that jejunostomy will be likely to replace other methods of securing rest in the treatment of gastric ulcer or of hæmatemesis, as Cackovie has suggested, and as has been adopted on one occasion with success by Mr. Willoughby Furner.

Modes of operation.-For any operation to be a success the bowel must be so placed that it will serve the two purposes: (1) to permit the passage onward of the bile and pancreatic fluid poured into the intestine above the artificial fistula; and (2) to allow of food being introduced through the fistula without fear of regurgitation, either of the food or of the intestinal contents. In my first operation, performed in 1891, I used a method which, though successful in prolonging life, was inconvenient and cumbersome and I need not mention it further.

The operations now used are the following:-1. A modification of Witzel's method of gastrostomy in which a No. 12 rubber catheter is stitched into an opening in the jejunum and afterwards the catheter is buried in a groove in the bowel for a distance of about two inches, the line of suture being fixed to the abdominal wall (see Figs. 1 and 2). 2. Maydl's method of dividing the jejunum, implanting the proximal cut end into the distal portion a few inches from the original line of section, the open end of this section being fixed to the skin (see Fig. 3). 3. The operation which I have performed and which I believe is new. It consists in taking a loop of the beginning of the jejunum just sufficiently long to reach the surface without tension; the two arms of the loop are short-circuited about three or four

1 A paper read before the Royal Medical and Chirurgical Society on April 11th, 1905. inches from the surface, the short-circuiting being done either by means of sutures around a decalcified bone bobbin or by sutures alone; personally I prefer the former. A small incision is then made into the top of the loop just large enough to admit a No. 12 Jaques catheter, which is Fig. 1.

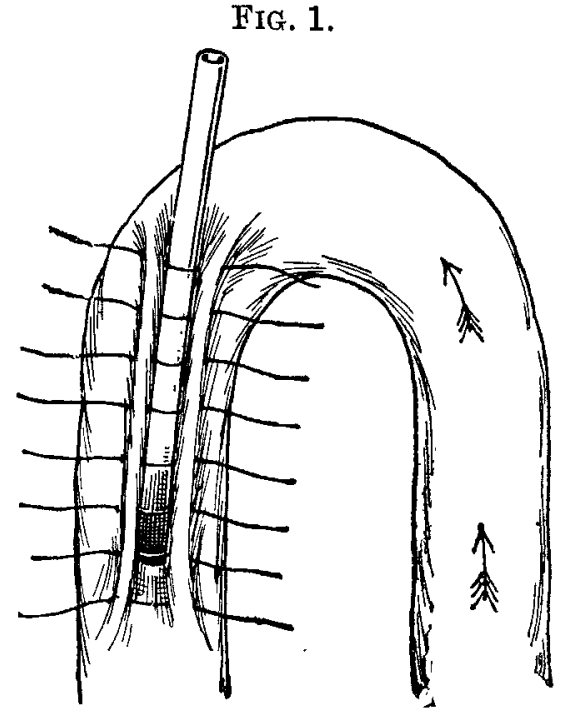

A method of performing jejunostomy by a modification of Witzel's operation for gastrostomy. First stage.

FIG. 2.

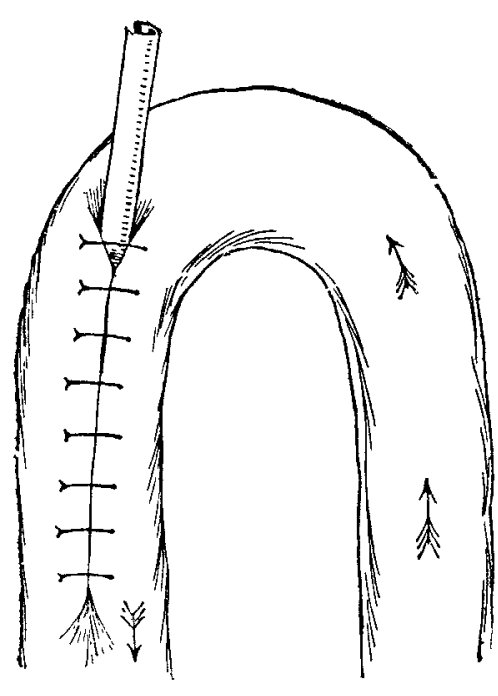

Second stage of Fig. 1 .

FIG. 3.

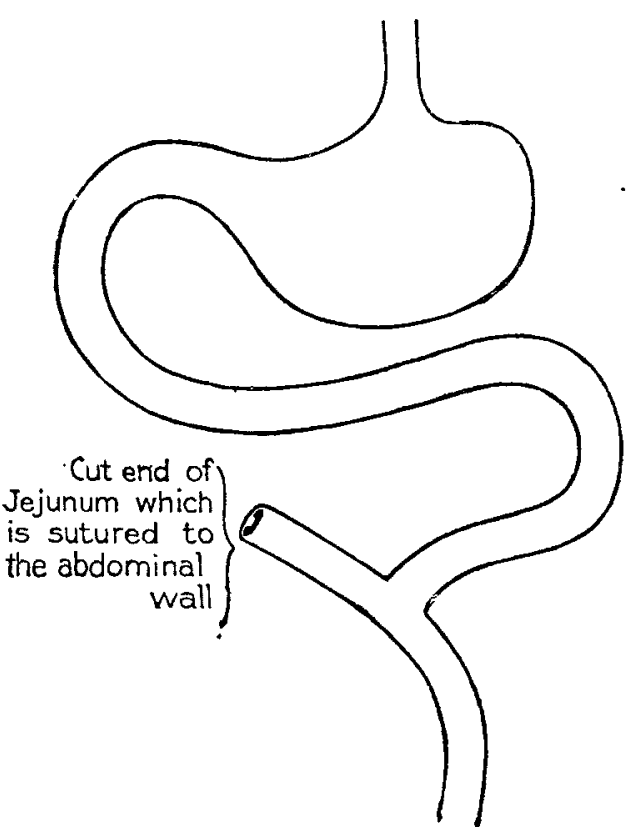

Jejunostomy by Maydl's method.

inserted and passed for three inches down the distal an of the loop; this is fixed to the margin of the incisio in the gut by a silk or Pagenstecher's suture and th entrance of the tube into the bowel is further guarde 